\title{
Avoidance in Family Creates Poor Mental Health in Children
}

\author{
Dr. Vikas Kamble ${ }^{1 *}$
}

\section{ABSTRACT}

Family relations are an essential factor for the overall development of child. It influences personality, attitude, thoughts and beliefs, social skills, emotional and psychological health. Children who are successful and well developed came from families where positive relationships existed between them and their parents, whereas children, who are discouraged and rejected at home they, might suffer from mental health problems. This assumption is tested in the present study. For this study 1620 children belonging in upper, middle and lower society ranged in age from 8 to 10 were randomly selected from different cities of Maharashtra states of India. Family relationship inventory and mental health questionnaire administered to the participated students. The obtained data analyzed by one-way analysis of variance. The results revealed that the mental health of children belonging in upper, and lower class society is affected due to the avoidance family relationships.

Keywords: Family Relations, Mental Health, and Different Social Groups.

Recently it is proved by the various researchers that family carry very crucial and significant role in the development of healthy personality by satisfying their essential requirements. Being the first unit of society, family manipulate the overall development of an individual such as cognitive, social, and emotional development. It is the very important context of development in which adolescent's various competencies are developed. Typically family is a context that reinforces adult values; promote school success and supports emotional security. Family members and quality of the relationship between them have led to coping with emotionally evocative situations. Larson and Richard (1991) convey that greater degree of family interaction especially with adolescents is developmentally beneficial.

Scientist in a various discipline such as psychologists, sociologists, educationists, etc. Believe that family provides the primary potential to healthy food for children for their better personality development and well-being. A healthy relationship between parents and siblings is essential for children's sound personality development. The quality of 'family relationships' depends on the

\footnotetext{
${ }^{1}$ Asst. Prof. Smt. Kasturbai Walchand College, Sangli, India *Responding Author

(C) 2016 V Kamble; licensee IJIP. This is an Open Access Research distributed under the terms of the Creative Commons Attribution License (http://creativecommons.org/licenses/by/2.0), which permits unrestricted use, distribution, and reproduction in any Medium, provided the original work is properly cited.
} 


\section{Avoidance in Family Creates Poor Mental Health in Children}

number of factors like nature of family constellation, the number of family members, parental employment and income, sibling relationship, and socio-economic and religious background of the family (Bala, 2011).

There are very few families were capable of supporting the physical as well as emotional requirements of the adolescents. Family conflicts lead the insecure feelings and emotional instability among the adolescence. If the parents behave more warmly and involved in their children's lives, then they express better. Sandler, Miller, Shart, Wolehik, (1989) were expressedthat warm, cohesive home environment with a low level of interpersonal conflicts do a better job of meeting children's physical and psychological needs as compared to the families characterized by high level of conflict and disengagement from each other.

Taken into account all above discussion it is seen that family relationship is most important factor in the wholesome development of children.

\section{Mental Health}

In recent days, mental health proves as a very potent role in various human life aspects as well in the life of society. Mental health is a potent determinant of one's integrated personality and balanced behavior identified by the level of his/her adjustment to own self, others and environment (Archana, 2011). There is no area in human life which is beyond the range of mental health. The term mental health does not refer to any one aspect of mental life or any one dimension of human personality. It encompasses all the aspects of the individual's adjustment with himself and others. If this adjustmentis characterized by wholesome personal, social, intellectual, emotional or philosophical orientations, the individual is deemed to have good mental health (Singh, 2011). Emotionally healthy individuals accept their weaknesses as well as their strengths. They remain in contact with reality, and they can deal with stress and frustration. Bowman (1965) defined mental health as the ability to function effectively and happily as one's expected role in a group. It is a condition of the whole of the mind as often supposed. It is an outgrowth of one's total life and is promoted or hindered by day to day experiences. Mental health implies the ability to judge reality accurately and to see things, regarding long term rather short term values. It implies the ability to love, to be able to sustain affectionate relationships with other persons. It means the ability to work in one's chosen field with pleasure and productivity. Mental health is a cognitive or emotional well-being and an absence of a mental disorder. From perspectives of the discipline of positive psychology, mental health may include an individual's ability to enjoy life and procure a balance between life activities and efforts to achieve psychological resilience.

Mental health is a psychological state of someone who is functioning at a satisfactory level of emotional and behavioral adjustment (WordNet, 2009). According to Wikipedia Dictionary (2010) mental health defined as a state of emotional and psychological well-being in which an 


\section{Avoidance in Family Creates Poor Mental Health in Children}

individual can use his or her cognitive and emotional capabilities, function in society and meet the ordinary demands of everyday life. Longman's Dictionary of Psychology and Psychiatry (Goldenson, 1984), states that mental health is a state of mind characterized by emotional wellbeing, relative freedom from anxiety and disabling symptoms, and coping with ordinary demands and stresses of life. According to WHO (2006) mental health is more than the absence of mental illness. It includes the ability to enjoy life, resilience, balance, flexibility, and selfactualization. Positive mental health consists of protection and development and satisfying human relationships and in the reduction of hostile tensions in persons and groups. Mental health involves positive feelings, positive attitude, and positive behavior. Mental health is something that has to be earned. But its learning does not depend upon the individual alone. In other words, the individual is rarely capable of achieving a satisfactory measure of good mental health exclusively through his/her personal efforts (Archana, 2013).

Thus byabove-mentioned explanations of mental health it can be concluded that the meaning of mental health differsby various disciplines such as psychologists, psychiatrists, education and others. It is influenced by a multiplicity of factors like intelligence, personality, education level, academic achievement, cultural level and physical health. Physical health and mental health are closely associated with each other. Mental health plays an important role in the way people behave and the way they feel.

\section{Aim of the study}

The present investigation is aimed at to study the effect of avoidance family relationships on the mental health of children.

\section{Objectives of the study}

1) To find out the influence of family avoidance relationship on the mental health of children belonging in anupper-class society of India.

2) To study the effect of family avoidance relationship on the mental health of children belonging in a middle-class society of India.

3) To investigate the impact of family avoidance relationship on the mental health of children belonging in a lower class society of India.

\section{Hypotheses of the study}

1) Low, average, and high avoidance family relationship will create different outcomes of mental health among the upper-class society of India.

2) Low, average and high avoidance family relationship will create different outcomes of mental health among the middle-class society of India.

3) Low, average and high avoidance family relationship will create different outcomes of mental health among the lower class society of India. 


\section{METHOD}

\section{Sample of the study}

A sample size of this study was high than any other common study. For this study 1620 children from different cities of the Maharashtra state of India were selected by the random sampling procedure. Their age ranged from 8 to 10 years. The sex ratiowas kept as 1:1.

\section{Tool used in the study}

\section{1) Family Relationship Inventory (FRI):}

Prepared by Sherry and Sinha (1987) by Brunken and Crites'Family Relationship Inventory in the Indian situations. The inventory is intended to identify the individuals who feel emotionally accepted, over protected or rejected by their parents. In other words, it measures the acceptance, concentration and avoidance tendency of parents. However in the present study, only acceptance tendency is considered. FRI includes 150 items with true false alternatives.Inventory has high reliability and validity. A high score in each area shows a high degree of one's feeling of his being accepted, concentrated and avoided by his or her parents.

\section{2) Mental Health Questionnaire:}

The Mental Health Scale Designed by Kamalesh Sharma, is used to measure the mental health of participants. It consists of 60 items in which 30 positive and 30 negative statements. Every statements have three alternative responses 'Yes', 'Indefinite' and 'No'. The test-retest with interval of two months and split half reliability is found .86 and .88 respectively. The validity coefficient is .79.

\section{Procedure}

Principals of the primary schools were contactedfirst, and permission was sought to collect the data from their school students. After the selection of every student in study their consent was taken to administer the psychology scale. Followed this procedure the group of 25 to 30 students has been made and the family relationship was administered with the help of research assistants.

\section{RESULTS AND DISCUSSION}

Table 1 Effect of Avoidance on Mental Health of Children in Upper-Class Society.

\begin{tabular}{|l|l|l|l|l|l|}
\hline $\begin{array}{l}\text { Sources of } \\
\text { Variance }\end{array}$ & Sum of Squares & df & Mean Square & F & Sig. \\
\hline Between Groups & 19391.233 & 2 & 9695.617 & 8.226 & .000 \\
\hline Within Groups & 632940.500 & 537 & 1178.660 & & \\
\hline Total & 652331.733 & 539 & & & \\
\hline
\end{tabular}

It can notice inTable1 that tendency of high, average and low avoidance family relationships creates the different outcomes in the mental health of upper-class society children $(F(2,537)=$ 8.226, $P<.000$ ). The between group mean is 9695.617 and within group mean is 1178.660 . This 


\section{Avoidance in Family Creates Poor Mental Health in Children}

result accepts the hypothesis, 'Low, average, and high avoidance family relationship will create different outcomes of mental health among the upper-class society of India.

Table 2 Effect of Avoidance on Mental Health of Children in Middle-Class Society.

\begin{tabular}{|l|l|l|l|l|l|}
\hline $\begin{array}{l}\text { Sources of } \\
\text { Variance }\end{array}$ & Sum of Squares & df & Mean Square & F & Sig. \\
\hline Between Groups & 8597.615 & 2 & 4298.807 & 276.101 & .000 \\
\hline Within Groups & 8360.933 & 537 & 15.570 & & \\
\hline Total & 16958.548 & 539 & & & \\
\hline
\end{tabular}

The one-way ANOVA in Table 2 showed the effect of family avoidance relationship on the mental health of middle-class society children. Between groups mean 4298.807 and within group mean 15.570 yielded $276.101 \mathrm{~F}$ value that is greater than the tabulated value shown on df 2, 537. This finding accepts the hypothesis, 'Low, average and high avoidance family relationship will create different outcomes of mental health among the middle-class society of India.'

Table 3 Effect of Avoidance on Mental Health of Children in Lower Class Society.

\begin{tabular}{|l|l|l|l|l|l|}
\hline Sources of Variance & Sum of Squares & df & Mean Square & F & Sig. \\
\hline Between Groups & 98708.226 & 2 & 49354.113 & 45.968 & .000 \\
\hline Within Groups & 576553.394 & 537 & 1073.656 & & \\
\hline Total & 675261.620 & 539 & & & \\
\hline
\end{tabular}

The one-way ANOVA in table 3 showed the effect of avoidance family relationship on mental health of high school students. Between groups mean 49354.113 and within group mean 1073.656 yielded $45.968 \mathrm{~F}$ value which is greater than the tabulated value shown on df 2, 537 . This finding accepts the hypothesis, 'Low, average and high avoidance family relationship will create different outcomes of mental health among the lower class society of India.

\section{CONCLUSIONS OF THE STUDY}

1) The mental health of children belonging toupper-class society is affected due to the family avoidance relationship.

2) The mental health of children belonging in middle-class society is affected due to the family avoidance relationship.

3) The mental health of children belonging in lower class society is affected due to the family avoidance relationship.

\section{Acknowledgments}

The author appreciates all those who participated in the study and helped to facilitate the research process. 


\section{Avoidance in Family Creates Poor Mental Health in Children}

\section{Conflict of Interests}

The author declared no conflict of interests.

\section{REFERENCES}

Archana, (2011) The study of Adolescence Mental Health in relation to Moral Judgment Intelligence and Perception.Doctoral dissertation Punjab University, Patiala.

Bala (2011).Psychosocial Predictors of Emotional Intelligence. Unpublished Ph. D. Thesis. Ravishankar Shukla University, Raipur.

Bowman (1965). Understanding Mental Health, New JursyOvans-Nostrand Company. Inc., 3340

Golden son, R. M. (1984). Longman’s Dictionary of Psychology and Psychiatry. Adison-Wesly, Longman Ltd. London.

Larson R. and Richards, N. H. (1991) Daily Companionship in Childhood and Adolescence, Charging Developmental Context. Child Development, Pp 62, 284 to 300

Sandler, Miller, P. Shart, J and Wolehik (1989). Social Support as a Protective Factor for Children in Sprees. In. Colon CliwerW, Fearnow, M. D. and Miller P. A. (1996) Coping

Socialization in Middle Childhood. Test of Maternal and Fraternal Influence. Child Development, 67, 2339 to 2357.

Singh (2011). Mental Health in Relation to Spiritual Intelligence, Ultraism, School Environment and Academic Achievement of Senior Secondary Students. Doctoral Dissertation, Gurunanak Dev Amrutsar University, Amrutsar.

How to cite this article: V Kamble (2016), Avoidance in Family Creates Poor Mental Health in Children, International Journal of Indian Psychology, Volume 3, Issue 4, No. 75, ISSN:23485396 (e), ISSN:2349-3429 (p), DIP:18.01.049/20160304, ISBN:978-1-365-50727-4 